\title{
Le management inter culturel au risque de la proxémique
}

\author{
Elizabeth Québriac et Alain Calmes
}

\section{OpenEdition}

\section{Journals}

Édition électronique

URL : https://journals.openedition.org/communicationorganisation/2467

DOI : 10.4000/communicationorganisation.2467

ISSN : 1775-3546

\section{Éditeur}

Presses universitaires de Bordeaux

\section{Édition imprimée}

Date de publication : 1 novembre 2000

ISSN : 1168-5549

Référence électronique

Elizabeth Québriac et Alain Calmes, «Le management inter culturel au risque de la proxémique », Communication et organisation [En ligne], 18 | 2000, mis en ligne le 27 mars 2012, consulté le 28 juin 2022. URL : http://journals.openedition.org/communicationorganisation/2467 ; DOI : https://doi.org/ 10.4000/communicationorganisation.2467

Ce document a été généré automatiquement le 5 août 2021 .

(C) Presses universitaires de Bordeaux 


\title{
Le management inter culturel au risque de la proxémique
}

\author{
Elizabeth Québriac et Alain Calmes
}

1 L'angle du management interculturel engendre un véritable décentrementrecentrement dans l'approche du langage silencieux en le liant indissociablement au relativisme culturel ${ }^{1}$. Le management interculturel est une préoccupation entrepreneuriale récente qui entérine - selon nous - bien souvent sans précaution les erreurs de la proxémique. L'entreprise contemporaine est fortement concernée par l'interculturalité. Cela en raison de l'internationalisation croissante des marchés, de l'exportation des modèles de gestion des ressources humaines, de la diversité des salariés et des cultures. Le croisement des cultures est un paramètre dont le management doit tenir compte. Par ailleurs la notion même de culture d'entreprise semble emprunter aux culturalistes nord américains sa définition extensive de la culture. Gérer c'est comprendre les mécanismes de la communication et à ce titre le langage silencieux concerne aussi l'entreprise. Masqués sans doute par la littérarité d'Edward Twitchell Hall, les défauts de la pensée proxémique étaient moins visibles auparavant. Importés tels quels par le management interculturel voici qu'ils ressortent avec une incontournable évidence en nous amenant à douter du tout. Le renouvellement des erreurs de la proxémique leur confère une visibilité qui permet de mieux s'en saisir. Cet examen des propositions du management interculturel vaut aussi - selon nous - comme lecture critique des approches communes en matière de langage silencieux. Tant la proxémique a fait partout force de loi en diffusant largement ses postulats.

\section{La maladie infantile de la proxémique}

2 La proxémique qui visait des objectifs pragmatiques a œuvré en ce sens sans trop de précautions ${ }^{2}$. Elle a développé deux attitudes qui s'excluent à nos yeux: le souci d'inscrire l'analyse du langage silencieux dans une optique de relativisme culturel d'une part et d'autre part la tendance à se contenter d'approximations grossières dès 
qu'elle compare les écarts existants entre les cultures en matière de code silencieux. Il en est de la proxémique pour le langage silencieux comme du macluhanisme pour les médias : c'est une approche séduisante et pionnière, pré-scientifique, dont la subite notoriété est due à une carence en analyses disponibles au moment où elle apparait. C'est précisément parce que la proxémique est une référence d'usage courant dans la recherche en matière d'approche des phénomènes du langage silencieux que le management interculturel a admis sans plus de précautions un certain nombre de ses présupposés.

$3 \mathrm{Au}$ tournant des années 50 les culturalistes américains donnent une définition extensive de la culture incluant tous les types de traits possibles. Ralph Linton énonce ceci : « Une culture est la configuration des comportements appris et de leurs résultats, dont les éléments composants sont partagés et transmis par les membres d'une société donnée $»^{3}$. Cette définition concerne les éléments du langage silencieux qui deviennent des traits culturels pertinents pour peu qu'ils soient partagés et transmis dans un groupe. Edward Terence Hall, chef de file des proxémistes américains, popularise dans Le langage silencieux et La dimension cachée, un certain nombre d'observations mettant en évidence l'importance du rapport au temps et à l'espace dans les cultures humaines. Ces dimensions y sont présentées comme les axes a priori, les principes premiers, organisateurs de la culture et de la communication humaine. La psychologie kantienne nous avait habitué à cette idée, mais cela n'avait jamais été démontré de manière aussi systématique. La maladie infantile de la proxémique c'est sans doute l'utilitarisme. Elle entend répondre à une demande et procède à la façon d'un guide pratique des conduites qui ignore les écarts et les variations subtiles. Toute la proxémique de Hall n'étant au fond qu'une tentative pour répondre à cette question lancinante et peut être parfois superflue : quelle est la bonne distance et le bon moment, ici, maintenant ?

\section{Les cinq défauts de la proxémique}

- La proxémique n'est pas neutre. Ses analyses tendent à conforter la conception de l'équilibre du monde reposant sur la supériorité supposée du bloc militaire, politique et scientifique nord américain. Elle divise le monde entre logique et illogisme selon une ligne de clivage Nord/Sud qui privilégie la rationalité et le temps économique anglosaxon. Elle aboutit, malgré l'invocation constante de la notion de relativisme culturel à un système arbitraire de confrontation des cultures du point de vue de la valeur. Prenons un exemple paradigmatique car il en existe tout un florilège. La proposition «Il nous faut trouver les moyens pour soustraire la vie au hasard et de la rendre heureuse. L'Amérique a beaucoup progressé dans ce domaine comparativement à d'autres peuples comme les Arabes et les Turcs, par exemple $»^{4}$ est nettement américanocentriste et rappelle la hiérarchisation macluhanienne des civilisations.

- La proxémique amalgame des jugements de valeur concernant les us et coutumes des peuples, comme s'il s'agissait de preuves scientifiques. Ainsi l'exemple suivant reflète un défaut criant dans le choix des sources :

«Le professeur Daniel Lerner, sociologue à MIT, s'est aperçu, en interrogeant des Turcs que l'idée d'accéder au bonheur ne signifiait rien pour eux. Il ne leur était jamais venu à l'esprit que le bonheur est un droit et qu'on peut chercher à en emplir son existence. Cela ne signifie pas que ces villageois n'étaient jamais heureux, mais simplement que leur culture n'incluait pas cette note $»^{5}$. 
6 Ce sophisme de référence participe clairement de cette illusion qu'une impression de seconde main tient lieu de preuve scientifique. Daniel Lerner, sociologue au MIT ne peut qu'avoir raison, c'est une référence scientifique probante pour Hall, même s'il n'a pratiqué aucune véritable enquête de terrain.

7 - La proxémique pratique la généralisation abusive. C'est, par exemple, une pratique constante chez Hall. Observer quelques indiens Pueblos permet de déduire la mentalité de tout un peuple. On retrouve ce mécanisme dans l'approche des cultures européennes :

«Beaucoup d'Européens pensent que faire la queue est une atteinte portée à leur individualisme. Je me rappelle un Polonais qui eut cette réaction. II disait que les Américains étaient des moutons et une telle passivité le poussait à se précipiter n'importe comment dans la foule qui attendait. Ces gens ne peuvent supporter d'être liés par la conformité d'un groupe comme s'ils étaient des robots ${ }^{6}$.

Certes, des écrits comme Un barbare en Asie d'Henri Michaux fourmillent de jugements outranciers et de généralisations de ce type, mais il s'agit de procédés littéraires explicites dans des types d'écrits qui n'aspirent à aucune scientificité.

- La proxémique utilise des opérateurs grossièrement construits. C'est un défaut corrélatif au précédent. Amenée à confronter les habitus culturels de millions d'individus elle ne s'appuie jamais sur des enquêtes méthodiques comme celle de 1TNSEE sur le mode de vie des Français. Tout se passe comme si les écarts culturels n'existaient pas dans une civilisation donnée: les peuples dont on divulgue les préférences proxémiques semblent tous agir comme un seul homme.

10 - La proxémique réduit les faits sociaux à son approche. Puisque la proxémie est la dimension cachée de la vie et de la société, on tend à trouver une explication proxémique à tout. Que cette prétendue cause déterminante soit passée inaperçue jusque là paraît une preuve supplémentaire. Ainsi Hall explique l'aveuglement du peuple américain devant le maccarthysme par l'ignorance de la dimension collective des normes :

«Une compréhension réelle de la culture devrait réveiller en nous cet intérêt à la vie qui nous manque si souvent, aider les gens à savoir où ils sont et ce qu'ils sont et à se défendre contre les plus cupides, voleurs et opportunistes de leurs congénères. Ces derniers se servent du fait que le public est généralement inconscient de ces normes formelles communes qui donnent à notre société sa cohérence. Ces laissés pour compte, auxquels il manque la sécurité des bases de la culture formelle, veulent détruire le monde et construire le pouvoir autour d'eux-mêmes. Le cas du sénateur Mac Carthy est un exemple classique de ce genre d'opportunisme. Si les Américains avaient compris que les normes formelles ne sont pas individuelles mais collectives, ils s'éviteraient le maccarthysme dans toutes ses manifestations culturelles $»^{7}$

11 Même si la condamnation du maccarthysme ne peut que susciter l'assentiment, l'analyse de cette idéologie intolérante est erronée. Il a été principalement engendré non par une méconnaissance du caractère collectif des normes mais par l'idéologie américaine des années cinquante et la politique des blocs de la guerre froide qu'on passe allègrement sous silence au profit d'une explication proxémiste des faits. C'est le principe même de causalité qui est déficient. Une carence à laquelle Mac Luhan nous a largement préparé, au demeurant.

12 - La proxémique adopte un ton péremptoire. Hall est conscient de l'importance du relativisme culturel comme le prouve la remarque suivante: «L'indétermination et la 
relativité culturelles sont des concepts difficiles à saisir pour l'homme de la rue [...] Une analyse culturelle adéquate doit commencer par une analyse micro-culturelle au niveau des notes $»^{8}$. Cela ne l'empêche pas d'assener des contre-vérités sans la moindre précaution oratoire, marque de l'objectivité et du relativisme qui viendrait tempérer ses assertions : « L'Allemand tend à être technique. L'Autrichien formel. Par conséquent l'Autrichien semble plus à l'aise »'.

\section{Comment le management interculturel réitère les défauts de la proxémique?}

13 L'importance des spécificités culturelles dans la gestion des ressources humaines est apparue à de nombreux chercheurs vers 1980. L'émergence de la notion de culture d'entreprise a rendu plus criante la méconnaissance des liens existants entre culture et entreprise. Le courant de pensée privilégiant la «corporate culture » et la notion de "productivity through people» s'est exprimé aux États-Unis dès $1982^{10}$. En France, Philippe d'Irribarne a bien résumé ce débat, mettant très tôt en évidence l'importance de la dimension interculturelle dans le management des entreprises ${ }^{11}$. Il souligne que l'interculturalité est un des facteurs émergents dont il faut tenir compte. Le projet du management interculturel ${ }^{12}$ consiste notamment à analyser les corrélations entre les modèles culturels nationaux et les styles de management et à donner des indications sur les conditions du dialogue avec des modèles étrangers. Cependant nombre de travaux de référence en matière de management interculturel aboutissent à des généralisations excessives qui rappellent les errements ethnocentristes et les erreurs de la proxémique. Si le croisement des cultures existe dans l'entreprise, son approche doit s'entourer des précautions méthodologiques classiques: désubjectivisation de l'objet étudié, pertinence statistique de l'échantillon, pertinence de la représentation construite des configurations culturelles dont on rend compte. Ce n'est pas chose aisée, ainsi Philippe Deval, a tenté de comparer dans Le Choc des cultures celles de différents pays : Japon, États-Unis, Allemagne, Angleterre, Espagne, Italie, Irlande et Pays-Bas. Ne disposant pas d'éléments statistiques fiables, il est parfois amené à simplifier à outrance. Cet ouvrage par ailleurs riche en exemples reproduit les vieux clichés sur la bonne distance :

«La proxémique revêt une grande importance aux États-Unis. La règle est la distance personnelle c'est-à-a dire que vous ne devez jamais transgresser l'espace de $1 \mathrm{~m} 20$ qui vous sépare de votre interlocuteur. Dans un primo-contact, la distance est de 2 à 4 mètres $»^{13}$.

Où, quand, comment, ce code implicite doit-il être observé ? Sur tout le territoire, quel que soit le lieu, la personne et le message? Par ailleurs, l'ouvrage compare la culture des firmes américaines et françaises. Il aurait fallu présenter des types d'écarts caractéristiques dans diverses entreprises en montrant les différences mais aussi les procédures communes. A l'échelle d'un pays aussi diversifié que les États-Unis, il faudrait disposer d'une enquête sociologique du type des grands instituts de sondage. Faute de quoi, on produira des vues très générales sur l'entreprise américaine. 


\section{Le rapport au temps et à la distance hiérarchique}

15 Le clivage entre pays nordiques et pays latins en matière de rapport au temps est souligné par nombre d'auteurs. La question du rapport au temps est même relativement centrale dans leurs représentations concernant le Sud. De même que la question des relations hiérarchiques dans les pays latins qui sont - selon eux - plus « individualistes ». Ainsi, l'enquête de Geert Hofstede sur la distance hiérarchique ${ }^{14}$ montre que les pays latins d'Europe, les pays d'Amérique du Sud et les pays d'Afrique noire se caractérisent par des régimes de longue distance hiérarchique, tandis que les pays anglo-saxons, Scandinaves et germaniques connaissent une distance hiérarchique courte. Hofstede va jusqu'à comparer sous la forme d'un graphique particulièrement tendancieux la position de cinquante trois pays sur l'échelle de la distance hiérarchique et de l'individualisme. Il amène ainsi le lecteur à prendre la carte des représentations collectives pour le territoire réel car ce graphique a été établi à partir des illusions du sens commun et non suite à une enquête systématique. Il est, certes, relativement difficile de rendre compte scientifiquement des modèles implicites de la culture, car tout ce qui ne donne pas lieu à des enregistrements concrets de comportements est aléatoire. Cela ne veut pas dire que ce qui touche aux processus mentaux des peuples n'est pas appréhendable. Ainsi, par exemple, l'attitude des Japonais dans la négociation constitue, selon nous, un phénomène d'apprentissage assez global et homogène pour que l'on puisse l'apprécier avec une certaine objectivité. C'est un rituel qui prend sa source dans les formes spécifiques de la socialisation japonaise :

«Les Japonais négocient en groupe et leurs décisions doivent faire l'objet d'un consensus. Ils doivent tous être d'accord. Afin d'éviter toute contestation et tout conflit, les Japonais organisent des discussions avant les réunions et consultent toutes les personnes qui y sont impliquées avant de parvenir à un consensus. Ce processus (nemawashi) commence au niveau des exécutants et remonte toute la hiérarchie pour arriver enfin, de façon informelle, jusqu'à l'autre partie $»^{15}$.

Les difficultés commencent dès que l'on ne se limite pas à un champ bien circonscrit et relativement homogène. Ainsi, autour de paramètres comme la distance hiérarchique dans l'entreprise et la gestion du temps, Philippe d'Irribarne compare longuement le "système français " et le "système américain ${ }^{16}$, Cette psychologie des mentalités collectives, pour séduisante quelle soit, ne doit pas faire perdre de vue le fait que dans les sociétés développées il existe des interpénétrations de systèmes plutôt que des systèmes purs. Relevons à ce titre, l'intérêt du concept « d'operating culture » de Ward H. Goodenough ${ }^{17}$. Pour cet auteur, une culture est un ensemble de croyances et de nonnes partagées par un groupe qui aide l'individu à décider. Un individu partage plusieurs cultures (ethnique, religieuse, professionnelle, d'éducation, de classe sociale, de classe d'âge) avec plusieurs groupes de personnes. Dans une situation particulière, l'individu choisit les éléments culturels adéquats pour obtenir le résultat escompté. Une évidence simple mais oubliée dans les analyses qui se réfèrent à des visions trop grossières des cultures nationales et d'organisation. Mais il est vraiment difficile de ne pas généraliser en matière de psychologie collective! Des analyses plus fines, tenant mieux compte des écarts dans une configuration donnée, sont absolument indispensables. Par exemple, il serait intéressant d'analyser les stratégies d'évitement des conflits des individus à temps $\mathrm{P}$ qui opèrent dans des dominantes à temps $\mathrm{M}$. et l'inverse. De même, se demander ce qu'il en est réellement, par de véritables enquêtes de terrain du clivage Nord/Sud en matière d'individualisme et de distance 
hiérarchique. Les modèles "purs » existent d'autant moins qu'on assiste à un fort brassage des individus et des modèles. Ces recommandations sont clairement exprimées dans un ouvrage récent consacré au temps et aux rites dans l'entreprise :

« En fait, il faut éviter de percevoir comme homogène ce qui ne l'est pas. De même que la gestion du temps et son vécu peuvent varier d'une entreprise à une autre, de même il existe des types de fonctionnement différents dans les entreprises contemporaines françaises et étrangères ${ }^{18}$.

\section{La carte peut cacher le territoire...}

Comment constituer des descripteurs valides des cultures? Pour être exhaustif dans la description d'une culture, il faudrait disposer d'une «carte» assez fidèle des groupements sociaux. Dans l'absence de ce type d'outil, comment rendre compte des tendances culturelles et sociales d'une communauté sans figer la réalité ou la distordre? En précisant la taille réelle du phénomène décrit, en cherchant systématiquement les variations, bref, en rendant compte des contradictions. C'est ce que fait Anne Marie Laulan lorsqu'elle limite son approche des différences Nord/Sud dans le management à un domaine bien circonscrit : les chocs culturels entre donneurs d'ordres parisiens «expatriés» et sous-traitants locaux niçois ou corses dans la technopole de Sophia Antipolis :

«L'une des sources de conflit, c'est le rapport au temps (à la ponctualité). Plus sérieuse est la différence des "génies». Le "génie» du Sud, décrit par les intéressés, c'est la capacité d'exercer et de mener à bien simultanément plusieurs actions. Les « étrangers » venus du Nord auraient un mode d'action séquentiel d'où les qualificatifs péjoratifs qu'ils attribuent aux méditerranéens: brouillons et désordonnés $»^{19}$.

18 De plus, son approche sait prendre de la distance avec les représentations des acteurs sociaux et n'essaie pas d'en tirer des lois générales. Si le management interculturel veut échapper aux pièges de l'ethnocentrisme et énoncer autre chose que des généralités peu fiables, il lui faut prendre conscience du fait que nombre d'idées reçues sur les cultures des communautés ou des peuples comportent des défauts d'optique. Dresser un tableau psychologique global des mentalités collectives relève de l'utopie. Tout au plus peut-on disposer d'une carte des attitudes observées sur des thèmes définis, qu'il faudra utiliser avec prudence. L'établissement et l'utilisation de cette « carte » doivent associer des observateurs liés aux communautés décrites.

Par ailleurs, si la proxémique a ouvert la voie à nombre de recherches il ne s'agit pas d'une science exacte. Il convient de ne pas tomber dans ses travers. Le fait que nous nous soyons attachés à les souligner ne comporte aucun a priori négatif sur l'œuvre par ailleurs riche et particulièrement captivante d'Edward Terence Hall. Mais pour bien l'utiliser il faut la délivrer de ses inévitables péchés de jeunesse. 


\section{NOTES}

1. Nombre de spécialistes de la communication non-verbale ont déjà abordé cette question. Voir par exemple «Similarities and differences between cultures in expressive movements » Eibl Eibesfeldt in Shirley Weitz : Non-verbal communication (readings). Oxford University Press, NewYork, 1974, p. 20.

2. Nous prenons nos exemples chez E.T. Hall, père de la proxémique américaine. Les défauts que nous recensons nous semblent paradigmatiques et récurrents dans la proxémique en général.

3. Ralph Linton, Le fondement culturel de la personnalité, Dunod, Paris, ed. 1988, p. 33.

4. Edward Terence Hall, Le langage silencieux, Seuil, Paris, ed. 1984, p. 214.

5. Le langage silencieux, p. 214.

6. Ibid, p. 203.

7. Ibid, pp. 212-213.

8. Le langage silencieux, p. 220.

9. Ibid, p. 150.

10. Voir Peters et Waterman, In Search of excellence Lessons from America's Best-Run Companies, Harper and Row, N.Y, 1980.

11. Philippe d'Irribarne, "Vers une gestion culturelle des entreprises ", Annales des Mines, septembre 1986 et «Cultures nationales et économie internationale », Futuribles, février 1990.

12. Voir notamment à ce sujet: Management interculturel, sous la direction de MM. GautheyXardel, Paris: Economica, 1991, L'interculturel en éducation et sciences humaines. Colloque. Publications de l'Université de Toulouse-Le Mirail, 1985.

13. Philippe Deval, Le choc des cultures, Eska, Paris, 1993, p. 69.

14. Daniel Bollinger et Geert Hofstede, Les différences culturelles dans le management: comment chaque pays gère-t-il ses hommes?, Editions d'Organisation, Paris, 1987. Selon ces auteurs "la distance hiérarchique se mesure à la perception que le subordonné a du pouvoir de son chef ", p. 82.

15. Enrique Ogliastri, « Négocier entre voisins éloignés : les négociations entre l'Amérique latine et le Japon", in La résistance culturelle, fondements, applications et implications du management interculturel, sous la direction de Pierre Dupriez et Solange Simons, De Boeck, Bruxelles, 2000. p. 177.

16. Philippe d'Irribarne, La logique de l'honneur. Seuil, Paris, 1983.

17. Ward H Goodenought, "Culture, langage and society », Modular Publication, $n^{\circ} 7$, Reading, Ma : Addison-Wesley Publishing CO, 1971.

18. Jean-Pierre Jardel et Christian Loridon, Les rites dans l'entreprise. Editions d'Organisation, Paris, 2000, p. 46.

19. Anne Marie Laulan, "Information et identités ", Actes du Colloque IAMCR-AIRI de Bled (ex Yu), 26-31 août 1990, dossier de la commission internationale de la SFSIC, 1990, p. 109.

\section{AUTEURS}

\section{ALAIN CALMES}

Université Rennes 2 